\title{
洞庭湖退田还湖及其生态恢复过程分析 *
}

\section{姜加虎 ${ }^{1}$ 张 琛 ${ }^{1}$ 黄 群 ${ }^{1}$ 邓学建 ${ }^{2}$}

(1: 中国科学院南京地理与湖泊研究所, 南京 210008; 2: 湖南师范大学, 长沙 410081)

\begin{abstract}
提 要 洞庭湖曾是我国第一大淡水湖泊, 盛期面积达 $6000 \mathrm{~km}^{2}$ 以上, 具有调蓄长江中游 洪水的巨大生态服务功能. 但经过近百年来的沧桑变诘, 湖泊发生了巨大变化, 由于泥沙的严 重淤积和围湖旺殖活动, 湖泊面积已萎缩至 $2625 \mathrm{~km}^{2}$, 为我国第二大淡水湖泊. 湖泊萎缩削弱 了其生态服务功能, 并由此引发了江湖洪水愈演愈烈的形势. 1998 年长江流域洪港灾害之后, 中国政府及时提出了“退田还湖” 等洪水治理的 32 字指导原则, 湖区各地随即积极开展了“退 田还湖、平垸行洪和移民建镇” 等工程. 本文针对湖区退田还湖双退堤垸的生态恢复过程, 选 择湖南省汉寿县的青山垸进行了跟踪研究. 结果显示了湖泊湿地恢复的阶段性特征, 并为我 国日益严重的湖泊富营养化问题的治理,提供了新的途径和可供参考的科学依据.
\end{abstract}

关键词 退田还湖 洞庭湖 生态环境 恢复过程

分类号 Q147

洞庭湖在长江中游荆江段南岸, 是目前长江中下游地区唯一与长江干流并联的通江湖 泊, 对于缓解长江中游地区的洪水压力, 具有十分重要的地位. 1998 年长江流域发生了洪涝 灾害, 中国政府及时提出了“退田还湖”等长江流域洪水治理 32 字指导原则, 湖区各地随即 根据水利规划, 积极实施 “退田还湖, 平垸行洪” 等工程. 规划平退堤垸 314 处, 平退总面积 $1578.7 \mathrm{~km}^{2}$, 耕地总面积 $758.7 \mathrm{~km}^{2}$, 计划搬迁 220549 户计 815965 人. 其中，双退堤垸 210 处, 双退总面积 $227.3 \mathrm{~km}^{2}$, 耕地总面积 $132.7 \mathrm{~km}^{2}$, 计划搬迁 48081 户计 174932 人. 通过 “退田还湖, 平垸行洪和移民建镇”工程的落实, 洞庭湖区增加有效总蓄洪量达 $86 \times 10^{8} \mathrm{~m}^{3}$, 在 特大洪水年份蓄洪堤垸和单退堤垸高水还湖可扩大湖泊面积 $1343 \mathrm{~km}^{2}$, 加上现有的天然湖泊 面积 $2625 \mathrm{~km}^{2}$, 洞庭湖面积达 $3968 \mathrm{~km}^{2}$. 目前, 又正在进行新一轮规划, 计划到 2010 年恢复洞 庭湖面积到 $4350 \mathrm{~km}^{2}$,达到新中国成立初期洞庭湖天然湖泊水域面积.

跟踪研究洞庭湖退田还湖的生态恢复过程, 不但是研究洞庭湖洪水调蓄功能的恢复, 同 时更重要的是研究湖泊湿地的生态环境修复过程, 为湖泊的治理、保护和生态恢复提供科学 依据. 在洞庭湖区诸多的退田还湖堤垸中, 本文选择了青山垸作为代表, 进行湖泊湿地生态 修复过程的范例研究.

\section{1 青山垸简介}

青山垸地处目平湖区, 沅江尾问南岸, 是洞庭湖区重点堤垸沅南大垸外的巴垸, 于 1976

* 中国科学院前沿领域项目和方向性项目 $(\mathrm{KXCX3}-\mathrm{SW}-331)$ 联合资助

$2003-08-28$ 收稿; 2003-10-31 收修改稿. 姜加虎, 男, 1962 年生, 研究员, E-mail: jiangjh@ niglas. ac. cn. 
年由蒋家嘴镇和洋淘湖农场联合围圼而成, 总面积 $11.1 \mathrm{~km}^{2}$, 其中耕地面积 $8.1 \mathrm{~km}^{2}$. 防洪大 堤堤长 $1.8 \mathrm{~km}$, 堤顶高程不足 $36.5 \mathrm{~m}$, 堤顶面宽不足 $2.0 \mathrm{~m}$, 是汉寿县的商品蔬菜和渔业的生 产基地, 但防洪能力薄弱, 镇辖居民多以种养为主. 1998 年长江洪水期间溃决, 洪水之后实 施了双退方式的退田还湖. 青山垸在退田还湖之前, 除水域区有少量典型的湿地动物外, 其 他地方完全由不畏人的庭院动物种群所占据. 野生动物小型化, 种类少, 多样性系数低, 动 物数量多集中在少数种类上. 除此之外, 家养动物占据了主要地位, 是当时的优势种群, 动 物群落完全人为化, 自然成分很少.

实施退田还湖后, 青山垸内的农民全部迁离, 垸内原来的一切人为设施全部废弃, 垸堤 河坝不再修复, 耕作和养殖地还湖. 至此, 原来的生态格局被完全打破, 植物逐步按照野生 状态形成新的生长模式. 动物群落也相应的发生了巨大的变化,依赖人类的动物纷纷离去 在以后的时间里, 湖区的代表性植物逐渐增多,野生动物接踵而来, 小型兽类和顶级动物（食 肉类动物)逐步进人, 新的生态格局通过自然调整而逐步恢复.

\section{2 退田还湖区(青山垸)湿地生态恢复过程}

\section{1 退田还湖区动物恢复过程}

经过历时近 3 年的 6 次调查 (表 1),在青山垸共遇见脊椎动物 389 次, 鉴定野生活体物 种 17011 只(条),共 104 种. 其中,遇见鱼类 62 次,鉴定个体 8255 条,共 27 种,隶属 6 目 10 科; 遇见两栖类动物 30 次,鉴定个体 741 只, 共 7 种, 隶属 1 目 4 科; 遇见爬行类 3 次, 鉴定 3 只共 1 种, 隶属 1 目 1 科; 遇见鸟类 281 次,鉴定 7884 只,共 66 种, 隶属 11 目 28 科; 遇见 哺乳类 13 次,鉴定 128 只,共 3 种,隶属 3 目 3 科。

表 1 洞庭湖青山垸退田还湖后动物的变化情况

Tab. 1 changes of animals in Qingshanwan, Dongting lake after stopping wltivation

\begin{tabular}{|c|c|c|}
\hline 次序 & 时 间 & 调查结果 \\
\hline 1 & 1999 年 5 月 $21-24$ 日 & $\begin{array}{l}\text { 调查的样带即涉及对照垸 (原青山垸情况), 青山垸 (退田还 } \\
\text { 湖后), 共有夏季鸟类 } 27 \text { 种, 隶属 } 8 \text { 日 } 21 \text { 科 }\end{array}$ \\
\hline 2 & $\begin{array}{l}1999 \text { 年 } 11 \text { 月 } 14-15 \text { 日，12 月 } \\
10-12 \text { 日；2000年 } 1 \text { 月 } 12-15 \text { 日 }\end{array}$ & 鸟类 30 种, 隶属 8 日 7 科; 鱼纲动物 24 种, 隶属 4 日 9 科 \\
\hline 3 & 2000 年 5 月 $3-6$ 日 & $\begin{array}{l}\text { 动物计 } 29 \text { 种 } 808 \text { 只, 其中两栖类 } 1 \text { 目 } 1 \text { 科 } 3 \text { 种; 鸟类有 } 9 \text { 目 } \\
19 \text { 科 } 26 \text { 种, 计 } 132 \text { 只 }\end{array}$ \\
\hline 4 & $\begin{array}{l}2000 \text { 年 } 10 \text { 月 } 3-4 \text { 日和 } 2001 \text { 年 } 1 \\
\text { 月 } 4 \text { 日、 } 27 \text { 日 }\end{array}$ & $\begin{array}{l}\text { 动物 } 55 \text { 种计 } 5133 \text { 只, 分别是鱼类 } 9 \text { 种 } 41 \text { 条, 隶属 } 3 \text { 目 } 4 \\
\text { 科; 两栖类动物 } 4 \text { 种 } 6 \text { 只, 隶属 } 2 \text { 目 } 2 \text { 科; 爬行动物 } 1 \text { 种 } 1 \\
\text { 条隶属 } 1 \text { 目 } 1 \text { 科; 鸟类 } 41 \text { 种 } 5085 \text { 只,隶属 } 13 \text { 目 } 22 \text { 科 }\end{array}$ \\
\hline 5 & 2001 年 3 月 $24-26$ & 乌类 15 种隶属 8 目 12 科 \\
\hline 6 & 2001 年 6 月 20 日 & $\begin{array}{l}\text { 鸟类 } 16 \text { 种, 隶属 } 6 \text { 目 } 12 \text { 科; 鱼类 } 3 \text { 种, 隶属 } 2 \text { 目 } 2 \text { 科; 两栖 } \\
\text { 类 } 5 \text { 种,隶属 } 1 \text { 目 } 2 \text { 科; 哺乳动物 } 3 \text { 种, 隶属 } 3 \text { 目 } 3 \text { 科 }\end{array}$ \\
\hline
\end{tabular}

\section{2 退田还湖区植被恢复过程}

2. 2.1 阁金口老堤 春季水边有黄花蒿 (Artemisia annua L.) 群落, 均为幼苗. 水生植物为 菹草 (Potamogeton crispus L.) , 夏季时水位升高, 植被 $98 \%$ 被水淹. 堤角房舍后的坡上主要 
有黄花藁、天名精 (Carpedium abrotanoides L. )、小飞蓬( Conyza canadensis L. Cronq. )、接骨草 (Sambucus chinensis Lindl. )、风轮菜（Clinopodium chinense (Benth.) O. Ktz. )、齿果酸模 ( Rumex dentatus L.) 等直立草本, 灌木有枸杞 (Lycium chinense Mell.) 等.

2.2.2 阁金口侧幸福垸内（1）原老房基: 出现的草本植物主要是碎米荠 ( Cardamine hirsute L. )、齿果酸模（Rumex dentatus L.）、臭莽（Coronopus didymus（L.）J. E.）、紫云英（Astragalus sinica L. )、荠菜（Cayratia bursa-pastoris (L. ) Medic. )、黄花蒿等 .

(2) 废稻田: 分两种情况,一种是地势偏高的油菜 (Brassica campestris L.) 地, 油菜为前一 年收割时散落的种子萌发而来, 演替出鹝草（Phalaris arundinaceae L.）＋油菜＋紫云英等 群落. 曧草呈丛生状态, 尚未连成片, 但扩展的趋势很明显, 是先锋植物. 夏季仅有鷊草群 落露出水面.

（3）阁金口外侧对照村落: 木本植物的种类变化不大．房舍周围蛇莓 (Duchesnea indica (Andrews) Focke）成了地被层的优势种，其次为水蓼（Polygonum hydropiper）和扬子毛茛 （Ranunculus sieboldii Miq.）．鱼塘埂上植物有白誉蒿（Artemisia lactiflora Wall.）、田边菊 (Aster panduratus Nees ex Walp.) 等。草本植被优势种已经由黄花蒿、荔枝草 (Salvia plebeia R. Br.）、窃衣（Torillis scabra (Thunb. ) DC. ）演替为小飞蓬、一年蓬（Erigeron annuus L. Pers. )、风轮菜、接骨草.

（4）朱家湾外堤内、外坡: 在水边至坡上 $3 \mathrm{~m}$ 地带上, 主要是植物的幼苗, 种类有蛇莓 (Duchesnea indica (Andrews) Focke)、荠菜、黄花蓠齿果酸模、紫云英、碎米荠（Cardamine hirsute L. )和白蔹蒿 .

此段样带植被演替比较明显, 1999 年的次优势种类球果澣菜（Rorippa globosa Turcz. Thellung）在 2000 年衰退；1999 年到 2000 年的优势种之一的窃衣在 2001 年消退；2000 年一 度成为优势种的飞蒹 (Carduus crispus L.)、荔枝草 (Salvia plebeia R. Br. ), 在 2001 年开始消 退.

（5）朱家湾青山垸内:（1)水塘,水生植物为发达的菹草群落. 塘埂上有紫云英群落.（2） 水渠, 有鹝草群落和紫云英群落. (3) 废宅基, 紫云英和鬲草为优势植物.（4) 废弃稻田,已经 演替出虉草丛.

\section{3 退田还湖区水环境变化过程}

通过跟踪退田还湖区水环境状况，以期弄清退田还湖对水环境的影响，退田还湖区的水 环境跟踪监测历时 3 年.

\section{1 退田还湖区水体的营养物质含量变化状况}

水体中氨态氮, 硝酸盐氮和总磷的含量, 可以基本反映退田还湖区水体的营养状况 . 通 过 3 年监测结果表明, 退田还湖后, 水体中的植物营养物质含量在退耕后的第二、三年出现 最高, 以后慢慢降低. 这可能是退田还湖区原为农民耕地（稻田、菜园地和桔园）、渔池和居 民点, 退田还湖被淹后, 环境中的氮、磷等各营养元素流失释放水体中, 使水体中氮、磷含量 增高, 但较之未退田还湖区还是低得多。由于退田还湖后多次淹水、退水变化, 退田还湖区 水体中氮、磷含量相应减少, 逐渐接近洞庭湖区天然湖泊、河流水体状况。 


\section{2 有机污染物化学耗氧量和生化耗氧量的变化}

退田还湖区水体中 $\mathrm{COD}$ 和 $\mathrm{BOD}_{5}$ 监测表明,有机物在退田还湖后呈缓慢上升, 然后又缓 慢下降的趋势,说明有机物的变化比植物营养元素变化缓慢 .

\section{3 水体 $\mathrm{pH}$ 值和电导率的变化}

退田还湖区水体 $\mathrm{pH}$ 值变化规律不明显, 水体 $\mathrm{pH}$ 值均在 6.5-8.0 范围内, 与沅江河水, 以及内湖、外湖和对照区无太大差别。电导率监测结果表明, 退田还湖区在开始的 $2-3$ 年, 水体电导率上升, 然后缓慢下降, 说明退田还湖后, 水体中离子含量较天然水体上升, 但随着 退田还湖时间延长和多次的淹水、退水,而逐渐接近天然水体水平。

\section{4 水体中其它污染物质含量的变化}

除对退田还湖区水体进行营养元素含量等监测外，还对重金属承、锰、六价铬、铅、铜、氟 和挥发酚, 以及大肠杆菌等进行了监测. 由于没有工业废水和生活废水的排人, 退田还湖区 原为农场与天然水体上述污染物含量也无甚区别 .大肠杆菌在头两年稍高，与退田还湖区 居民点生活污染有关,而挥发酚有时监测稍高一点可能与捕鱼船只影响有关.

\section{5 不同生境条件水质差别}

堤垸、渔塘、稻田、老宅基和林地 (均系退耕前) 5 个生境点,退田还湖后水质监测结果表 明, 不同生境条件退耕后其水质大有差别. 老宅基由于是居民点, 退田还湖后, 其水环境质 量较差, 特别是氮、磷的含量高, 其余依次为稻田、堤垸、林地和渔塘, 其水质依次要好, 但与 对照点洋淘湖农场的渔塘、井水、安乐湖（内湖）和沅江主河道水质比较, 退田还湖区水质在. 头两年虽比不上天然水体, 但比洋淘湖渔塘水质要好. 随着时间延长, 水质指标逐渐按近天 然水体.

总之, 退田还湖区由于季节性的淹水、退水, 水体中的氨态氨、硝态氮、总磷含量在头 $2-3$ 年会是明显增高,在老宅基、稻田及部分堤垸可出现轻度水体富营养化,但随时间延长, 这种作用越来越小.COD、BOD 5 具有缓慢上升后，再缓慢下降的趋势，电导率也有类似耗氧 有机物的变化特征, 其它污染物质含量则相对甚低, 与天然水体无大差别 . 说明退田还湖区 正逐渐恢复天然状态,其水质指标也逐渐接近天然水体.

\section{4 退田还湖区土壤中小型动物变化}

\section{1 种群时空格局及其动态变化差异性大}

土壤中无脊椎动物群落的组成有 5 门 15 纲, 动物种群空问结构水平分布差异性, 依不 同地理环境、生态结构类型、土壤理化性质等, 其种类和数量水平分布是菜地 $>$ 林地 $>$ 湖中 高台耕作地 > 池塘岸地 > 湖中湿地>堤垸坚地>废弃宅基地. 垂直分布为表层土 0 $5 \mathrm{~cm}>$ 浅层土 $(5-10 \mathrm{~cm})>$ 较深层土 $(10-15 \mathrm{~cm})$; 大型无脊椎动物以表层土中的物种丰富度 最高, 中小型动物以 $5-10 \mathrm{~cm}$ 深处分布密度大、种类多. 但这种现象常受环境条件 (气温、雨 水和光照等因素) 制约, 从而出现时间上季节性动态差异, 如秋末 $\rightarrow$ 冬季, 土壤动物受低温影 响逐渐向较深层运动, 表现为中层 $(5-10 \mathrm{~cm})>$ 表层土 $(0-5 \mathrm{~cm})=$ 深层土; 春季 $\rightarrow$ 初夏, 动 物向上层转移, 表现为表层土> 中层土> 深层土. 盛夏时期受高温影响, 或干旱时动物又转 人深层土, 呈现为深层土> 中层> 表土层 


\section{2 土壤动物分布及与土壤植被、理化性质的关系密切}

土壤团粒结构较好, 土质松、疏,通气条件好,有机质较丰富, 植被覆盖度好, 栖息的动物 种类多、数量 (或密度) 大 (或高), 如蔬菜地、果林地. 反之, 长期淹水, 许多动物因缺游离氧 而无法生存;完全裸露或长期扳结、不通气或无腐殖质的土壤中动物分布较少.

\section{3 动物的种类和数量增加迅速}

经过退田还湖 2 年多时间的变化或演替, 动物种类和数量逐渐上升, 如 2001 年 6 月与 1999 年 5 月底相同样点, 动物个体数量前者是后者的 10 倍以上, 说明土壤动物种群发育良 好,稳定性不断增大。

\section{5 结语}

通过对洞庭湖退田还湖区生态恢复过程的跟踪监测，研究表明退田还湖区的湿地生态 自然恢复过程主要需要经过三个阶段。

（1）生态结构混乱期, 即由于实施退田还湖后, 环境的变化造成原来稳定的动物群落结 构崩溃,生态结构无序, 时间为 1 年左右.

（2）新的生态格局初现期, 该时期的湿地生态结构很不稳定 . 整个时期, 典型湿地植物 逐渐取代原有的人工作物, 人工作物在野生状态下逐渐被淘汰, 典型的湿地鸟类逐渐渗人, 动植物形成不稳定的群落结构. 在此条件下, 再进一步演替出现湿地兽类, 即顶级动物逐年 渗人,时间为 $2-4$ 年.

（3）稳定的野生湿地生态生物群落期, 经过生物群落的重新调整、自然演替或恢复,逐步 构成了新的湿地生物种群结构. 动植物完全按照野生状态进行生长繁衍, 彼此构成了较稳 定的生态关系,估计时间大约需 4-5 年时间 .

从洞庭湖青山垸在退田还湖后的湖泊湿地生态结构恢复过程显示, 自然界具有强大的 生态修复和自我调整能力, 而且这一过程的发展应该说还是很快的. 面对我国经济较发达 地区湖泊水体日趋富营养化问题，该研究结论提供湖泊富营养化治理和水生生态修复的例 证，表明对湖泊的生态治理，人们既要有足够的信心和投人，又要充分尊重自然规律和耐心 等待, 相信大自然生态自我恢复的能力, 问题的关键在于湖泊内部生态区的合理规划和有效 管理,避免一边投巨资进行湖泊环境污染治理,一边又忽视湖泊内部生态管理，出现边治理、 边破坏的矛盾局面。

致 谢 在论文完成过程中得到了世界自然基金会(WWF)的大力支持和资助。

\section{参 考 文 献}

1 秦伯强。长江中下游浅水湖泊富营养化发生机制与控制途径初探. 湖泊科学,2002,14(3):193-202

2 所东茹, 吴振斌. 富营养化浅水湖泊沉水水生植被的衰退与恢复. 湖泊科学, 1997,9(1):82-88

3 成水平. 人工湿地废水处理系统的生物学基喽研究进展. 湖泊科学, 1996,8(3):267-272

4 贺建林,杨友效, 曹明德等。洞庭湖区湖洲生态建设初探一以沅江市湖洲为例。湖泊科学, 1998,10(4):77-82

5 窦鸿身,姜加虎等。洞庭湖，合肥:中国科学技术大学出版社,2000

6 张 梨, 李世成, 刘月英. 洞庭湖及其周围水域的双壳类软体动物. 动物学报, 1965,17(2):197 213 


\title{
Analysis on the Restoration and Ecological Recovery of Dongting Lake by Stopping Cultivation
}

\author{
JIANG Jiahu, ZHANG Shen, HUANG Qun \& DENG Xuejian \\ ( I: Nanjing Institute of geography and Limnology, Chinese Academy of Sciences, Nanjing 210008, P. R. China; \\ 2: Hunan Normal University, Changsha 410081, P. R. China)
}

\begin{abstract}
Dongting lake, which had been the largest fresh water lake of china with an area of more than $6000 \mathrm{~km}^{2}$, plays a significant role in adjusting runoff of the middle Yangtze river. Dongting Lake has dramatically changed for the past 100 years, of which the area has reduced to $2625 \mathrm{~km}^{2}$ up to now, and becomes the second largest fresh water lake for the serious siltation of mud and sand. The reduction of the area results in the diminishment of the ecological function, and also leads to the more serious flood and degeneration of the wetlands. The guide principles of floods control of the Yangtze catchment, which refers to restoring lake by stopping cultivation, was implemented by the central government after the flood disaster in 1998, and the projects including " restoring lakes by stopping cultivation" etc have been carried out in the area of the Dongting Lake. In the article, the process of ecological restoration of Dongting Lake by stopping cultivation is analysed in Hanshou County of Hunan Province as the experimental area. The results present a staggered feature of restoration of the wetlands, and offer new way and scientific experiemental basis to harness the problem of eutrophication in lakes and wetlands.
\end{abstract}

Keywords: Restoring lake by stopping cultivation; Dongting Lake; ecological environment; process of restoration 